\title{
FERMENTATION OF BIODIESEL-DERIVED WASTE FOR 1,3-PROPANEDIOL PRODUCTION WITH RESPONSE SURFACE METHODOLOGY
}

\author{
STASHA ELEANOR ROSLAND ABEL* and SOH KHEANG LOH*
}

\begin{abstract}
The present study aimed to investigate the fermentation conditions favouring the maximum production of 1,3-propanediol (1,3-PD) from crude glycerol. Response surface methodology (RSM) based on central composite design (CCD) was applied in designing the experiments to evaluate the interactive effects of glycerol concentration (20 to $50 \mathrm{~g}$ litre $\left.e^{-1}\right), \mathrm{pH}(6$ to 8$)$, temperature $\left(30^{\circ} \mathrm{C}\right.$ to $40^{\circ} \mathrm{C}$ ) and incubation time (48 to $72 \mathrm{hr}$ ) on 1,3-PD production. A total of 30 experimental runs consisting of 16 factorial points, eight axial points and six centre points were conducted. It was found that the derived optimum conditions were: $39.9 \mathrm{~g} \mathrm{litre}^{-1}$ glycerol; $\mathrm{pH}: 7.6$, temperature: $33^{\circ} \mathrm{C}$ and incubation time: $59.1 \mathrm{hr}$. Under these conditions, the 1,3-PD produced (9.85 $\left.\mathrm{glitre}^{-1}\right)$ was $\sim 2 \%$ higher than the predicted value by RSM $\left(9.69 \mathrm{~g} \mathrm{litre}^{-1}\right)$, hence, the experimental design employed in validating the results obtained was significant. The analysis of variance (ANOVA) showed high coefficient of the determination values $\left(R^{2}\right)$ of 0.9444 . The fermentation using RSM was able to increase the 1,3-PD production by two-fold.
\end{abstract}

Keywords: 1,3-propanediol, bioprocess, biodiesel by-product, central composite design, optimisation.

Date received: 8 December 2016; Sent for revision: 9 December 2016; Received in final form: 30 January 2017; Accepted: 2 February 2017.

\section{INTRODUCTION}

Biodiesel, an environmental-friendly biofuel compared to fossil fuel, is made from plant oils, animal fats and recycled greases. The glycerol to biodiesel production ratio is 1:10 (Yang et al., 2012). The rapid development of the biodiesel industry in recent years has generated an inevitable abundance of waste glycerol, the application of which is limited as compared to pure glycerol due to the presence of impurities. Thus, it is economically beneficial to convert this by-product into higher value products, in order to improve the sustainability of the biodiesel business and overcome environmental challenges associated with crude glycerol disposal.

Malaysian Palm Oil Board, 6 Persiaran Institusi,

Bandar Baru Bangi, 43000 Kajang,

Selangor, Malaysia.

E-mail: stasha.eleanor@mpob.gov.my
At present, considerable efforts have been devoted to explore the potential applications of crude glycerol as valuable products such as biofuels, chemicals, polymers and animal feed. The bioconversion via biological routes seems to be more practical and feasible as it will be able to circumvent the disadvantages of conventional processes (Da Silva et al., 2015). A wide range of value-added products could be obtained through the microbial fermentation of crude glycerol. These include polyhydroxyalkanoates (PHA), 1,3-propanediol (1,3-PD), citric acid, hydrogen and many others. Among the many promising applications for glycerol, microbial conversion into 1,3-PD has received much attention especially in recent years. Therefore, the main objective of this study is to utilise crude glycerol as low-cost carbon source to produce 1,3-PD via the biological approach.

The 1,3-PD is a starting material used in polymerisation, mainly in polytrimethylene terepht- 
halate (PTT) manufacturing. It can be synthesised chemically. However, the chemical route entails expensive catalysts, higher temperature and pressure condition as well as extreme safety measures for handling. In contrast, the biological route is more desirable as it is fermentation-based, uses low-cost raw materials and is safe. Hence, converting glycerol into 1,3-PD via the bioprocess route seems promising due to the better economics, more environmental-friendly and plus the fact that the production yield is much higher compared to chemical synthesis as proven in previous studies (Jun et al., 2010; Wilkens et al., 2012).

Biologically, glycerol can be used to make valuable chemicals, e.g. 1,3-PD (Loh and Stasha, 2016; Jun et al., 2010), citric acid (Morgunov et al., 2013), succinic acid (Sadhukhan et al., 2016), ethanol (Chanthoom et al., 2016) and butanol (Jensen et al., 2012). Previously, several bacteria species had been identified for their ability to produce 1,3-PD such as Klebsiella (Wojtusik et al., 2015), Clostridium (Szymanowska-Powalowska, 2014), Enterobacter (Waghmare and Naik, 2016) and Citrobacter (Ferreira et al., 2012). Among these, K. pneumoniae is one of the most studied because it has been evidently shown to have potential for glycerol synthesis into 1,3-PD with high productivity (Jalasutram et al., 2011; Rossi et al., 2012; Da Silva et al., 2015).

As the fermentation conditions play an important role in achieving maximum 1,3PD production, the optimisation of the culture condition is desired. According to Ibrahim et al. (2011), the conventional 'one-factor-at-a-time' (OFAT) approach is less practical because the estimation of the factor effects is imprecise and leads to an incomplete understanding of the research findings. Besides, the OFAT system is time-consuming due to the requisite of performing a number of experimental runs. These limitations can be replaced by optimising the factors via designing a statistical experiment using response surface methodology (RSM).

RSM is a useful model for designing and analysing the experiments statistically in determining the optimal conditions desirable for the responses with minimum run of experiments by assessing the relative significance of numerous independence variables (Sivasubramanian and Namasivayam, 2014). RSM constitutes various techniques, for instance, central composite design (CCD), one factor design, Box-Behnken design and the historical data design. The CCD is more desirable that is ideal for sequential experimentation and doesn't involve a huge number of design points. Several studies have successfully utilised CCD for the optimisation process of 1,3-PD (Hong et al., 2013; Li et al., 2014). The present study attempted applying RSM to evaluate the combined effect of $\mathrm{pH}$, temperature, incubation time and concentration of glycerol on the production of 1,3-PD.

\section{MATERIALS AND METHODS}

\section{Materials}

Crude glycerol was obtained from Sime Darby Biodiesel Sdn Bhd (Selangor, Malaysia). The properties of crude glycerol are 79.3\% glycerine, $6.69 \%$ water, $16.2 \%$ soap, $7.3 \%$ methanol and $0.97 \%$ oil. All chemicals were purchased from SigmaAldrich (USA) and Merck.

\section{Microorganism, Inoculum Preparation and Culture Conditions}

The commercial bacterium, Klebsiella pneumoniae, was used throughout this study. This bacterium was purchased from the Unit of Bacteriology, Institute for Medical Research (IMR), Kuala Lumpur, Malaysia. The strain was cultured on growth medium containing ( $\mathrm{g}$ litre $\left.{ }^{-1}\right)$ : yeast extract, 5; peptone, 10; $\mathrm{NaCl}$, 9; glycerol, 20 and agar, 20. Mineral salt medium (MSM) consisted of $\left(\right.$ g litre $\left.{ }^{-1}\right): \mathrm{K}_{2} \mathrm{HPO}_{4^{\prime}} 0.69 ; \mathrm{KH}_{2} \mathrm{PO}_{4^{\prime}} 0.25 ;\left(\mathrm{NH}_{4}\right)_{2} \mathrm{SO}_{4^{\prime}} 6$; $\mathrm{MgSO}_{4} \cdot 7 \mathrm{H}_{2} \mathrm{O}, 0.2$; yeast extract, 1.5 and $1 \mathrm{ml}$ of trace element solution was used as the basal medium for the experiments. The solution consisted of $(\mathrm{mg}$ litre $\left.{ }^{-1}\right): \mathrm{MnSO}_{4} \cdot 4 \mathrm{H}_{2} \mathrm{O}, 100 ; \mathrm{ZnCl}_{2}, 70 ; \mathrm{Na}_{2} \mathrm{MoO}_{4} \cdot 2 \mathrm{H}_{2} \mathrm{O}$, 35; $\mathrm{H}_{3} \mathrm{BO}_{3}, 60 ; \mathrm{CoCl}_{2} \cdot 6 \mathrm{H}_{2} \mathrm{O}, 200 ; \mathrm{CuSO}_{4} \cdot 5 \mathrm{H}_{2} \mathrm{O}, 29.3$; $\mathrm{NiCl}_{2} \cdot 6 \mathrm{H}_{2} \mathrm{O}, 25$ and $0.9 \mathrm{ml}$ of $37 \% \mathrm{HCl}$ solution.

\section{Analytical Methods}

For the seed culture, the strain was grown on the growth medium overnight. The 1,3-PD fermentation was conducted in a 250-ml Erlenmeyer flask containing $100 \mathrm{ml}$ of the basal MSM and $10 \%(\mathrm{v} / \mathrm{v})$ seed culture at varying conditions according to the experimental design as described in Table 1. During the cultivation, the culture samples were taken at specific time interval and centrifuged at $4000 \mathrm{rpm}$ for $10 \mathrm{~min}$ to remove cells. The supernatant was then filtered through a nylon-based membrane filter $(0.45$ $\mu \mathrm{m})$. The concentration of 1,3-PD was measured by a high performance liquid chromatography (HPLC) system with a refractive index detector (RID). A mobile phase i.e. aqueous sulfuric acid $(0.5 \mathrm{mM})$ was

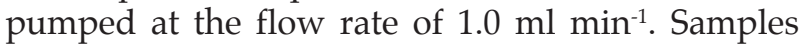
injection and metabolites analysis was conducted at $60^{\circ} \mathrm{C}$. All experimental trials were conducted in triplicate.

\section{Experimental Design and Optimisation by RSM}

CCD was employed to firstly determine the optimum culture conditions and secondly 
to show the statistical significance of the four independent variables $(\mathrm{pH}$, incubation time, glycerol concentration and temperature) in 1,3$\mathrm{PD}$ production. The experiments were designed using Design-Expert ${ }^{\circledR}$ software (version 9.0, StatEase, Inc. Minneapolis, USA). The CCD primarily consists of a $2^{4}$ factorial experimental design which has 16 factorial points, eight axial points and six replicated centre points leading to 30 runs covering the full design of four variables investigated at five different levels $(-\alpha,-1,0,1,+\alpha)$ as illustrated in Table 1. The presence of curvature of response and estimation of pure error were examined by applying the replicated center points (Mabilia et al., 2010). In developing the regression equation, the variables were coded according to Equation (1):

$$
x_{i}=\frac{\left(X_{i}-\bar{X}_{i}\right)}{\Delta X_{i}} i=1,2,3 \ldots . k
$$

Equation (1)

where $x_{i}$ is the independent variable coded value, $X_{i}$ the independent variable real value, $X_{i}$ is the independent variable real value at centre point and $\Delta X_{i}$ the value of step change. The response variable was fitted into a second order model polynomial [Equation (2)] in order to correlate the response variable to the independent variables.

$$
Y=\beta_{0}+\sum \beta_{i} x_{i}+\sum \beta_{i i} x_{i}^{2}+\sum \beta_{i j} x_{i} x_{j} \quad \text { Equation (2) }
$$

where $Y$ is the predicted response, $\beta_{0}$ is the offset term, $\beta_{\mathrm{i}}$ is the linear effect, $\beta_{\mathrm{ii}}$ is the quadratic effect, $\beta_{\mathrm{ij}}$ is the interaction effect and $x_{i}$ represents the coded value of variables. The variable $x_{i} x_{j}$ represents the first-order interaction between $x_{i}$ and $x_{j}(i<j)$.

The Design-Expert ${ }^{\circledR}$ software was used to fit the second-order polynomial model and was statistically validated by performing analysis of variance (ANOVA). ANOVA is essential to test the significance and adequacy of the model. It subdivides the total variation of the results into two sources of variation, the model and the experimental error to show whether the variation from the model is significant when compared to the variation due to residual error. The fitness and accuracy of the model was determined by $R^{2}$ coefficient and F-test was used to check the statistical significance of the model. The main and interactive effects of the independent variables on the dependent ones were illustrated by the three-dimensional surface.

\section{RESULTS AND DISCUSSION}

\section{Model Fitting and ANOVA}

The maximum production of 1,3-PD by K. pneumoniae was achieved using the CCD based method of RSM. The experimental design matrix and their employed responses are presented in Table 2. The predicted values were obtained with a model fitting technique using Design-Expert ${ }^{\circledR}$ software and were seen to be sufficiently correlated with the experimental values. In our study, the ANOVA showed that the model was most suitably described with a quadratic polynomial model. The results of the second-order response surface model for the 1 , 3-PD production in the form of ANOVA are listed in Tables 3 and 4, respectively.

The model was highly significant as demonstrated by the quadratic regression of ANOVA, as was evident from the low $P$-value of the F-test $(18.20)\left[\mathrm{P}_{\text {model }}>\mathrm{F}\right)=<0.0001$. The model also showed a statistically insignificant lack of fit, as was evident from the lower calculated $F$-value (0.17) i.e. the desired probability value (0.1) for lack of fit; hence indicated that the model was valid for the present work and can be used to predict the response (Suhaila et al., 2013). Among the linear terms, the main ones, i.e. $\mathrm{pH}$ and temperature for 1,3-PD production were highly significant as were shown by their respective $P$-values $\left(P x_{1}=<0.0001\right.$ and $\mathrm{P} x_{4}=0.0001$ ).

Glycerol concentration also showed a significant effect although in lesser degrees compared to $\mathrm{pH}$ and temperature in producing 1,3-PD $\left(\mathrm{P} x_{3}=0.0041\right)$. In contrast, the incubation time was insignificant in affecting 1,3-PD production with $P$-values $>0.05$ $\left(\mathrm{P} x_{2}=0.3982\right)$. Based on the ANOVA, significant interactions were found between glycerol and

TABLE 1. EXPERIMENTAL RANGE AND LEVEL OF THE INDEPENDENT VARIABLES

\begin{tabular}{ccccccc}
\hline & Variable & \multicolumn{5}{c}{ Range and level } \\
\cline { 3 - 6 } Factor & $\boldsymbol{- \alpha}$ & $\mathbf{- 1}$ & $\mathbf{0}$ & $\mathbf{1}$ & $+\boldsymbol{\alpha}$ \\
\hline & $\mathrm{pH}$ & 5 & 6 & 7 & 8 & 9 \\
$\mathrm{X}_{1}$ & Temperature $\left({ }^{\circ} \mathrm{C}\right)$ & 25 & 30 & 35 & 40 & 45 \\
$\mathrm{X}_{2}$ & Incubation time $(\mathrm{hr})$ & 36 & 48 & 60 & 72 & 84 \\
$\mathrm{X}_{3}$ & Glycerol concentration $\left.(\mathrm{g} \mathrm{litre})^{-1}\right)$ & 5 & 20 & 35 & 50 & 65 \\
$\mathrm{X}_{4}$ & & & & & \\
\hline
\end{tabular}

Note: $x_{1}$ - coded value of the variable $X_{1}$

$x_{1}$ - (pH-7)/1; $x_{2}$ - (temperature-35)/5; $x_{3}$ - (incubation time-60)/12; $x_{4}$ - (glycerol concentration-35)/15. 
TABLE 2. COMPOSITION OF THE VARIOUS RUNS OF THE CENTRAL COMPOSITE DESIGN, ACTUAL AND PREDICTED RESPONSES

\begin{tabular}{|c|c|c|c|c|c|c|}
\hline \multirow[t]{2}{*}{ Run No. } & \multirow{2}{*}{$\begin{array}{l}\text { Factor } 1 \\
\mathrm{pH}\left(\mathrm{X}_{1}\right)\end{array}$} & \multirow{2}{*}{$\begin{array}{c}\text { Factor } 2 \\
\text { Temperature } \\
\left(\mathrm{X}_{2}\right)^{\circ} \mathrm{C}\end{array}$} & \multirow{2}{*}{$\begin{array}{c}\text { Factor } 3 \\
\text { Time }\left(X_{3}\right) \text { hr }\end{array}$} & \multirow{2}{*}{$\begin{array}{c}\text { Factor } 4 \\
\text { Glycerol }\left(X_{4}\right) \\
\text { concentration } \\
\text { g litre }{ }^{-1}\end{array}$} & \multicolumn{2}{|c|}{ Response (1,3-PD) g litre ${ }^{-1}$} \\
\hline & & & & & Actual value & Predicted value \\
\hline 1 & $7(0)$ & $35(0)$ & $60(0)$ & $65(+\alpha)$ & 5.10 & 4.58 \\
\hline 2 & $7(0)$ & $35(0)$ & $36(-\alpha)$ & $35(0)$ & 4.28 & 4.61 \\
\hline 3 & $7(0)$ & $25(-\alpha)$ & $60(0)$ & $35(0)$ & 4.24 & 4.53 \\
\hline 4 & $6(-1)$ & $30(-1)$ & $72(1)$ & $50(1)$ & 5.66 & 5.30 \\
\hline 5 & $7(0)$ & $35(0)$ & $60(0)$ & $35(0)$ & 10.65 & 8.97 \\
\hline 6 & $7(0)$ & $35(0)$ & $60(0)$ & $5(-\alpha)$ & 1.28 & 1.97 \\
\hline 7 & $8(1)$ & $30(-1)$ & $72(1)$ & $20(-1)$ & 4.78 & 4.35 \\
\hline 8 & $8(1)$ & $30(-1)$ & $48(-1)$ & $20(-1)$ & 5.37 & 5.49 \\
\hline 9 & $8(1)$ & 40 (1) & $48(-1)$ & $50(1)$ & 4.19 & 4.05 \\
\hline 10 & $6(1)$ & $40(1)$ & $72(1)$ & $20(-1)$ & 1.39 & 1.11 \\
\hline 11 & $8(1)$ & $40(1)$ & $48(-1)$ & $20(-1)$ & 5.02 & 5.00 \\
\hline 12 & $8(1)$ & $40(1)$ & $72(1)$ & $50(1)$ & 2.17 & 3.53 \\
\hline 13 & $8(1)$ & $30(-1)$ & $72(1)$ & $50(1)$ & 7.29 & 7.59 \\
\hline 14 & $8(1)$ & $30(-1)$ & $48(-1)$ & $50(1)$ & 7.49 & 7.39 \\
\hline 15 & $6(-1)$ & $40(-1)$ & $48(-1)$ & $20(-1)$ & 2.08 & 1.98 \\
\hline 16 & $7(0)$ & $35(0)$ & $60(0)$ & $35(0)$ & 9.69 & 8.97 \\
\hline 17 & $7(0)$ & $35(0)$ & $60(0)$ & $35(0)$ & 10.13 & 8.97 \\
\hline 18 & $6(-1)$ & $40(1)$ & $48(-1)$ & $50(1)$ & 1.29 & 1.34 \\
\hline 19 & $7(0)$ & $35(0)$ & $84(+\alpha)$ & $35(0)$ & 4.09 & 3.94 \\
\hline 20 & $7(0)$ & $35(0)$ & $60(0)$ & $35(0)$ & 8.46 & 8.97 \\
\hline 21 & $6(-1)$ & $40(1)$ & $72(1)$ & $50(1)$ & 1.71 & 1.81 \\
\hline 22 & $6(-1)$ & $30(-1)$ & $72(1)$ & $20(-1)$ & 1.39 & 1.74 \\
\hline 23 & $6(-1)$ & $30(-1)$ & $48(-1)$ & $50(1)$ & 3.72 & 4.10 \\
\hline 24 & $7(0)$ & $35(0)$ & $60(0)$ & $35(0)$ & 7.81 & 8.97 \\
\hline 25 & $8(1)$ & $40(1)$ & $72(1)$ & $20(-1)$ & 3.32 & 3.14 \\
\hline 26 & $7(0)$ & $45(+\alpha)$ & $60(0)$ & $35(0)$ & 0.68 & 0.56 \\
\hline 27 & $6(-1)$ & $30(-1)$ & $48(-1)$ & $20(-1)$ & 2.90 & 1.89 \\
\hline 28 & $9(+\alpha)$ & $35(0)$ & $60(0)$ & $35(0)$ & 7.70 & 7.52 \\
\hline 29 & $7(0)$ & $35(0)$ & $60(0)$ & $35(0)$ & 7.07 & 8.97 \\
\hline 30 & $5(-\alpha)$ & $35(0)$ & $60(0)$ & $35(0)$ & 1.84 & 2.20 \\
\hline
\end{tabular}

TABLE 3. ANALYSIS OF VARIANCE (ANOVA) FOR 1,3-PD PRODUCTION RESPONSE SURFACE REDUCED QUADRATIC MODEL

\begin{tabular}{|c|c|c|c|c|c|}
\hline Source & Sum of squares & DF & Mean Square & F value & Prob $>$ F \\
\hline Model & 226.51 & 14 & 16.18 & 18.20 & $<0.0001$ \\
\hline Residual & 13.34 & 15 & 0.89 & - & - \\
\hline Lack of fit & 3.43 & 10 & 0.34 & 0.17 & 0.9909 \\
\hline Pure error & 9.91 & 5 & 1.98 & - & - \\
\hline Cor total & 239.85 & 29 & - & - & - \\
\hline
\end{tabular}

Note: SD - 0.94; CV - 19.71; R² - 0.9444; Adj R² - 0.8925; Pred R² - 0.8582; Adeq precision - 12.607

temperature $(\mathrm{P}<0.05=0.0084)$. The quadric effects of all factors were also found highly significant. Using the findings from the designed experiment (Table 2), the polynomial model for the 1,3-PD production $(Y)$ was regressed by only considering the significant terms as in Equation (3):

$$
\begin{aligned}
& Y=8.97+1.33 X_{1}-0.17 X_{2}+0.65 X_{3}-0.99 X_{4}-0.71 X_{3} X_{4} \\
& -1.03 X_{1}^{2}-1.17 X_{2}^{2}-1.42 X_{3}^{2}-1.60 X_{4}^{2} \quad \text { Equation (3) }
\end{aligned}
$$

where $Y$ is the predicted response (1,3-PD production) and $X_{1}, X_{2}, X_{3}$ and $X_{4}$ are the coded values of the independent variables; $\mathrm{pH}$, temperature, incubation time and glycerol concentration, respectively. The quadratic model in Equation (3) with 10 terms contained four linear terms, four quadratic terms and one two factorial interactions.

The goodness of fit of the model as examined by the model determination coefficient, $R^{2}$ was very close to 1.0, thus the better the model fits the experimental data and predicts the response. The $R^{2}$ was found to be 0.9444 , which implied that the model had $94.44 \%$ of the observed response attributed to the variables and their interactions. 
TABLE 4. MODEL COEFFICIENT ESTIMATED BY MULTIPLIES LINEAR REGRESSION

\begin{tabular}{lccc}
\hline Factor & $\begin{array}{c}\text { Coefficient } \\
\text { estimate }\end{array}$ & $\begin{array}{c}\text { Standard } \\
\text { error }\end{array}$ & P value \\
\hline Intercept & 8.97 & 0.38 & $<0.0001^{*}$ \\
$\mathrm{X}_{1}$-pH & 1.33 & 0.19 & $<0.0001^{*}$ \\
$\mathrm{X}_{2}$-Time & -0.17 & 0.19 & 0.3982 \\
$\mathrm{X}_{3}$-Glycerol & 0.65 & 0.19 & $0.0041^{*}$ \\
$\mathrm{X}_{4}$-Temperature & -0.99 & 0.19 & $<0.0001^{*}$ \\
$\mathrm{X}_{1} \mathrm{X}_{2}$ & -0.25 & 0.24 & 0.3089 \\
$\mathrm{X}_{1} \mathrm{X}_{3}$ & -0.078 & 0.24 & 0.7451 \\
$\mathrm{X}_{1} \mathrm{X}_{4}$ & -0.14 & 0.24 & 0.5506 \\
$\mathrm{X}_{2} \mathrm{X}_{3}$ & 0.33 & 0.24 & 0.1767 \\
$\mathrm{X}_{2} \mathrm{X}_{4}$ & -0.18 & 0.24 & 0.4547 \\
$\mathrm{X}_{2} \mathrm{X}_{4}$ & -0.71 & 0.24 & $0.0084^{*}$ \\
$\mathrm{X}_{1}{ }^{2}$ & -1.03 & 0.18 & $<0.0001^{*}$ \\
$\mathrm{X}_{2}{ }^{2}$ & -1.17 & 0.18 & $<0.0001^{*}$ \\
$\mathrm{X}_{3}{ }^{2}$ & -1.42 & 0.18 & $<0.0001^{*}$ \\
$\mathrm{X}_{4}{ }^{2}$ & -1.60 & 0.18 & $<0.0001^{*}$ \\
\hline
\end{tabular}

Note: *Values of 'probability $>$ F value' less than 0.05 indicate model terms are significant.

Yet, only $5.56 \%$ of the total variance could not be explained by the model. These measures indicated that the model fitted well in optimising 1,3-PD production (response) as the polynomial model used was capable of generating accurate data and the response trends analysed was reasonable. Meanwhile, the model's significance level was confirmed by the value of the adjusted $R^{2}(0.8925)$ which was very close to the predicted $R^{2}(0.8582)$.

The model showed the ratio of signal to noise $>4$ i.e. 12.607, hence was indicative of adequate model discrimination (Ramanan et al., 2010). This ratio indicated the reliability of the experiment data and the higher model adequacy to predict the response. The coefficient of variation $(\mathrm{CV}=19.71)$ and standard deviation $(S D=0.94)$ of the model further indicated the higher degree of precision. The low values of $\mathrm{CV}$ reflected that reliable and precise experiments had been conducted.

\section{Response Surface Plots Analysis}

The 3D response surface generated from the regression model illustrated the interactive effects of each independent variable on the response. Figure 1 shows an example of the effects of two variables in producing 1,3-PD, while the other two variables were constant at their middle levels. It further shows that only glycerol concentration and temperature had significant interactions as displayed in Figure 1. Previously, the convex response surfaces suggested that the model used was well-defined in providing optimal solutions. This otherwise indicated that the optimised values may differ very little from single variable conditions, if the response surfaces were rather flat and symmetric near the optimum point.

\section{Model Validation with the Optimised Culture Conditions}

The optimal culture conditions as predicted by RSM: $\mathrm{pH}=7.6$; incubation time $=59.1 \mathrm{hr}$; glycerol concentration $=39.9 \mathrm{~g}$ litre $^{-1}$ and temperature $=33^{\circ} \mathrm{C}$ were verified. The experiments performed showed pretty close predicted and experimental values (9.69 $\mathrm{g}$ litre $^{-1}$ vs. $\left.9.85 \mathrm{~g} \mathrm{litre}^{-1}\right)$ confirming that the model used was valid with the existence of an optimal point. The optimisation via RSM may improve 1,3PD production by two-fold as compared with that under unoptimised condition (Table 5).

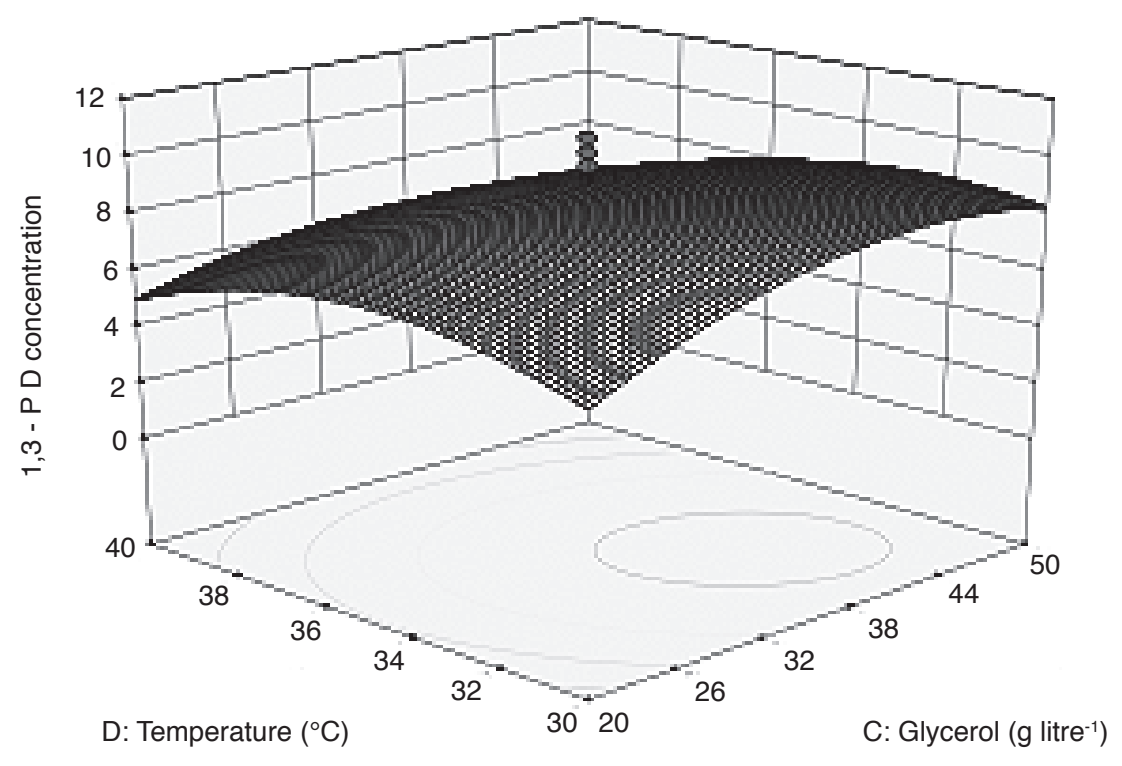

Figure 1. The 3-D graphic plots showing the effect of glycerol concentration and temperature on 1,3-PD production. Value of $\mathrm{pH}$ and incubation time was fixed at central point. 
TABLE 5. EXPERIMENTAL VERIFICATION OF COMBINED EFFECT OF OPTIMISED CONDITION ON THE RESPONSE OF 1,3-PROPANEDIOL (1,3-PD) PRODUCTION

\begin{tabular}{|c|c|c|c|c|c|}
\hline \multirow{3}{*}{ Variables } & \multirow{3}{*}{$\begin{array}{l}\text { Unoptimised } \\
\text { condition }\end{array}$} & \multirow{3}{*}{$\begin{array}{l}\text { Optimised } \\
\text { condition }\end{array}$} & \multicolumn{3}{|c|}{ 1,3-PD production (g litre ${ }^{-1}$ ) } \\
\hline & & & \multirow[t]{2}{*}{ Before optimisation } & \multicolumn{2}{|c|}{ After optimisation } \\
\hline & & & & Predicted & Experimental \\
\hline $\mathrm{pH}$ & 7 & 7.6 & - & - & - \\
\hline Temperature $\left({ }^{\circ} \mathrm{C}\right)$ & 30 & 33 & 4.89 & 9.69 & 9.85 \\
\hline Incubation time (hr) & 48 & 59.1 & - & - & - \\
\hline $\begin{array}{l}\text { Glycerol concentration } \\
\qquad\left(\mathrm{g} \text { litre }^{-1}\right)\end{array}$ & 20 & 39.9 & - & - & - \\
\hline
\end{tabular}

\section{CONCLUSION}

Temperature and $\mathrm{pH}$ were shown to be the most significant in influencing the process performance of 1,3-PD followed by glycerol concentration, whereas incubation time showed the least influence. The RSM-based CCD study revealed that the interaction between incubation temperature and glycerol concentration had profound impact, which was vital in achieving exponential increase in 1,3-PD production. The findings were beneficial for future research looking into cost-effective production of 1,3-PD from biodiesel-derived waste.

\section{ACKNOWLEDGEMENT}

The authors thank the Director-General of MPOB for permission granted to publish this article.

\section{REFERENCES}

CHANTHOOM, K; TANIKKUL, P; SIRISUKPOKA, U and PISUTPAISAL, N (2016). Ethanol production form biodiesel-derived crude glycerol by Enterobacter aerogenes. Chemical Engineering Transactions, 50: 211216.

DA SILVA, G P; BOLNER DE LIMA, C J and CONTIERO, J (2015). Production and productivity of 1,3-propanediol from glycerol by Klebsiella pneumoniae GLC29. Catalysis Today, 257: 259-266.

FERREIRA, T F; RIBEIRO, R D R; RIBEIRO, C M S; FREIRE, D M G and COELHO, M A Z (2012). Evaluation of 1,3-propanediol production from crude glycerol by Citrobacter freundii ATCC 8090 . Chemical Engineering Transactions, 27: 157-162.

HONG, E; YOON, S; KIM, J; KIM, E; KIM, D; RHIE, $S$ and RYU, Y W (2013). Isolation of microorganisms able to produce 1,3-propanediol and optimization of medium constituents for Klebsiella pneumoniae AJ4. Bioprocess and Biosystems Engineering, 36: 835-843.
IBRAHIM, H M and ELKHIDIR, E E (2011). Response surface method as an efficient tool for medium optimisation. Trends in Applied Sciences Research, 6: 121-129.

JALASUTRAM, V; JETTY, A and ANUPOJU, G R (2011). Fermentative conversion of raw glycerol into 1,3-propanediol by isolated Klebsiella pneumoniae 141B stain: optimization of culture variables. African J. Biotechnology, 10(80): 18493-18502.

JENSEN, T O; KVIST, T; MIKKELSEN, M J; CHRISTENSEN, P V and WESTERMANN, P (2012). Fermentation of crude glycerol from biodiesel production by Clostridium pasteurianum. J. Industrial Microbiology and Biotechnology, 39: 709-717.

JUN, S A; MOON, C; KANG, C H; KONG, S W; SANG, B I and UM, Y (2010). Microbial fed-batch production of 1,3-propanediol using raw glycerol with suspended and immobilized Klebsiella pneumoniae. Applied Biochemistry and Biotechnology, 161: 491-501.

LI, L; ZHOU, S; JI, H; GAO, R and QIN, Q (2014). Optimization of fermentation conditions for 1,3-propanediol production by marine Klebsiella pneumonia HSL4 using response surface methodology. Chinese J. Oceanology and Limnology, 32(5): 1036-1045.

LOH, S K and STASHA, E R A (2016). Conversion of crude glyycerol to 1, 3-propanediol by newly isolated kluyvera cryocrescens. J. Oil Palm Res. Vol. (28): 222-227.

MABILIA, R; SCIPIONI, C; VEGLIO, $\mathrm{F}$ and SCIANO, M C T (2010). Fractional factorial experiments using a test atmosphere to assess the accuracy and precision of a new passive sampler for the determination of formaldehyde in the atmosphere. Atmospheric Environment, 44: 3942-3951.

MORGUNOV, I G; KAMZOLOVA, S V and LUNINA, J N (2013). The citric acid production 
from raw glycerol by Yarrowia lipolytica yeast and its regulation. Applied Microbiology and Biotechnology, 16: 7387-7397.

RAMANAN, R N; TAN, J S; MOHD, S M; LING, T C; TEY, B T and ARBAKARIYA, A (2010). Optimization of osmotic shock process variables for enhancement of the release of periplasmic interferon-a $2 b$ from Escherichia coli using response surface method. Process biochemistry, 45: 196-202.

ROSSI, D M; DA COSTA, J B; DE SOUZA, E A; PERALBA, M D C R and AYUB, M A Z (2012). Bioconversion of residual glycerol from biodiesel synthesis into 1,3-propanediol and ethanol by isolated bacteria from environmental consortia. Renewable Energy, 39(1): 223-227.

SADHUKHAN, S; VILLA, $\mathrm{R}$ and SARKAR, U (2016). Microbial production of succinic acid using crude and purified glycerol from a Crotalaria juncea based biorefinery. Biotechnology Reports, 10: 84-93.

SIVASUBRAMANIAN, $\mathrm{S}$ and NAMASIVAYAM, S K R (2014). Statistical optimization of physical conditions for phenol degradation using effective microorganism-I. The Indian J. Medical Research, 21: 14-20.

SUHAILA, Y N; RAMANAN, R N; ROSFARIZAN, M; LATIF I A and ARIFF, A (2013). Optimization of parameters for improvement of phenol degradation by Rhodococcus UKMP-5M using response surface methodology. Annals of Microbiology, 63: 513-521.

SZYMANOWSKA-POWALOWSKA, D (2014). 1,3-Propanediol production from crude glycerol by Clostridium butyricum DSP1 in repeated batch. Electronic J. Biotechnology, 17: 322-328.

WAGHMARE, T and NAIK, G R (2016). Microbial production of 1, 3-propanediol using newly isolated Enterobacter cloacae GNTEW13-1, GNTEW13-V and its enhancement studies by UV mutagenesis. International J. Current Microbiology and Applied Sciences, 5(7): 953-960.

WILKENS, E; RINGEL, A K; HORTIG, D; WILKE, T and VORLOP, K D (2012). High-level production of 1,3-propanediol from crude glycerol by Clostridium butyricum AKR102a. Applied Microbiology and Biotechnology, 93(3): 1057-1063.

WOJTUSIK, M; RODRIGUEZ, A; RIPOLL, V; SANTOS, V E; GARCIA, J L and GARCIAOCHOA, F (2015). 1,3-Propanediol production by Klebsiella oxytoca NRRL-B199 from glycerol. Medium composition and operational conditions. Biotechnology Reports, 6: 100-107.

YANG, F; HANNA, M A and SUN, R (2012). Valueadded uses for crude-glycerol - a byproduct of biodiesel production. Biotechnology for Biofuels, 5: 13. 